\title{
Managerial attitudes: influences on workforce outcomes for working women with chronic illness
}

Published in Economic and Labour Relations Review (2015) vol 26, no 2.

\author{
Shalene Werth \\ Griffith University and University of Southern Queensland, Australia
}

Corresponding author:

Shalene Werth, School of Management and Marketing, Faculty of Business, Education, Law and Arts, University of Southern Queensland, Toowoomba QLD 4350 Australia.

Email: werths@usq.edu.au.

\begin{abstract}
Individual managers may make judgments and decisions which reflect social expectations rather than organisational policy. Society generally requires that individuals with an illness take leave from their work, seek medical assistance and return when they are well. This is not possible for individuals with chronic illness. By its nature, chronic illness has no cure. Individuals who are diagnosed with diseases such as rheumatoid arthritis, diabetes or inflammatory bowel disease and who also undertake paid employment, may need to disclose their illness and seek some form of accommodation in their workplace. Understanding attitudes of managers play a significant role in the success of managing work and chronic illness. This paper examines the working experiences of women with chronic illness where the attitudes of managers were less understanding.
\end{abstract}

\section{JEL codes: M50}

\section{Keywords}

Chronic illness, disability, disclosure, discrimination, diversity, employment security, reasonable accommodation, women, work, workforce participation.

\section{Introduction}

Disability support organisations and policy makers have, for some time, been calling for individuals with disability (this includes those with chronic illness) to play a greater role in the workforce. The Australian National Disability Strategy (2010) revealed that there are social and economic benefits associated with workforce participation. The difficulty lies in bridging the gap between managers' knowledge that people with disability and chronic illness are capable of working and the level of understanding that they need in order to enable women with chronic illness to enter or remain in the workforce.

In 2014 the National Disability Forum, convened by the Australian Human Rights Commission, conducted a survey which was designed 'to consult with the disability rights sector and wider community about the key issues affecting persons with disabilities' (Australian Human Rights Commission, 2014: 3). Respondents ranked work and employment second only after participation and inclusion in society, as the most important human rights issues currently facing persons with disability: he survey offered a choice of 16 options. This study also found that 'stereotypes and negative attitudes towards persons with disability are too prevalent, both across the community and among employees' (Australian Human Rights Commission, 2014: 8).

Society generally requires that individuals with an illness take leave from their work, seek medical assistance and return when they are well. This is not possible for individuals 
with chronic illness. By its nature, chronic illness has no cure. Individuals who are diagnosed with diseases such as rheumatoid arthritis, diabetes or inflammatory bowel disease and who also undertake paid employment, may need to disclose their illness and seek some form of accommodation in their workplace.

A number of factors have been identified which create barriers or enablements to maintaining a role in the workforce for people with chronic illness. These include the existence of workplace policy and levels of support (Charmaz, 2010) as well as the attitudes of managers (Pinder, 1995). This article examines the influence that lack of understanding, on the part of managers and workplaces, exert on the workforce outcomes of women with chronic illness. The data used are drawn from interviews with 24 women with chronic illness who had previously been in the workforce or who were currently working. Their experiences highlight the role played by employer support in their ability to remain in the workplace.

The analysis uses an element of the disclosure contingency pathways model (Werth, 2013) to examine the specific role that managerial attitudes play in the outcomes of women with chronic illness. This simplified version of the disclosure contingency pathways diagram (Figure 1) shows the way in which managerial attitudes, the severity and variability of illness and the type of flexibilities available to workers interact to influence the accommodations which those with chronic illness are able to access: these in turn influence their workforce outcomes. Existing literature conceptualising each of these factors will first be examined, followed by a discussion of the use of 'insider methodology' in the study. The discussion focuses on the experiences of a number of women who reported varied workforce outcomes as a result of varying degrees of employer support.

\section{Managerial attitudes and expectations}

Previous research on the impact of managerial attitudes on workers with chronic illness or disability does not paint a particularly hopeful picture. Foster (2007: 73) found that 'approximately half of those interviewed said that they had experienced stress and ill health as a consequence of the workplace adjustment [or accommodation] process'. Once a chronic illness has progressed to the point where some form of accommodation is required, the worker needs to disclose additional information about their impairment. This can have the effect of marginalising the worker, particularly in workplaces where expectations are based on an 'ableist' conceptualisation of the ideal worker (Foster and Wass, 2013). 'Ableism' is a term used to signify discriminatory attitudes associated with disability: it is used in similar ways to the term 'sexism' which denotes negative attitudes based on gender. Foster and Wass observed that:

In the same way that feminists observed that women would continue to be disadvantaged in the labour market because jobs were designed around male norms, disabled people will never achieve organisational 'fit' when jobs are designed around ableism (2013: 718).

Promotion, within workplaces, of particular perceptions of a typical or ideal worker has resulted in the use of ableist norms to determine the value of workers who continue to work whilst they have a chronic illness.

Managerial perceptions of the ideal worker influence the way that colleagues within the workplace respond to a colleague with a disability: in this way these understandings of disability are reinforced throughout the workgroup (Williams-Whitt, 2007). Where workplaces are less supportive, many disabled workers 'struggle to secure basic, but essential alterations to their working arrangements and environment' (Foster and Fosh, 2010: 577). This may be, at least in part, because 'requesting an adjustment can be interpreted as a challenge to managerial prerogative' (Foster and Wass, 2013: 717). 
Women with chronic illness, in addition to their impairment, must also contend with their caring responsibilities. Societal acknowledgement of women's caring responsibilities and how they influence their conditions at work has evolved gradually over time (Pocock, 2003; Vickers et al., 2004). Despite some gains in this area, women affected by chronic illness are still in a more precarious position in the workplace because of existing perceptions of what constitutes a productive or ideal worker. These women find it difficult to conform to such expectations (Vickers, 2012). Work-life balance for individuals with chronic illness is complicated by the need for flexible working conditions based on a greater understanding for their life circumstances. Vickers (1997) reports that women with chronic illness are often denied the 'assumption of competence' in their place of employment. Individuals with disability or chronic illness who request an adjustment or assistance due to their impairment may appear to question the authority of management in the workplace (Foster and Wass, 2013).

Where managerial attitudes can be adjusted, Foster and Wass point out that 'an abstract job could be designed around the skills and competencies of a non-standard employee' (2013: 716-717). They go on to say that the 'complex design of many modern jobs [are] organized on largely unchallenged assumptions of what constitutes a typical or ideal worker. Ableist norms, like gendered norms, have shaped the world of work and continue to do so' (Foster and Wass, 2013: 716-717). William-Whitt and Taras add that 'employers must do more than attempt to fit someone who is disabled into a position designed for someone who is not' (2010: 534).

\section{Simplified disclosure contingency pathways}

The influence of managerial support on the disclosure decision and on the outcomes of workers with chronic illness evident in the simplified disclosure contingency pathways (Werth, 2013). It should be acknowledged that there are a wide range of factors which impact on the workforce outcomes of women with chronic illness. This paper focuses on the influence that managerial support or lack of support has on workforce outcomes

The disclosure contingency pathways diagram (Figure 1) shows the potential outcomes of working where accommodations for chronic illness are either available or not. Decisions about how to manage work depend on the attitudes experienced in the workplace, the severity and variability of symptoms and whether workers use general or contingent flexibilities. The issue of managerial attitudes towards employees with various types of disabilities is a topic which is increasingly under scrutiny by researchers both in Australia and overseas. Some notable papers on the topic include: Vickers (2012), Vickers (2003), Charmaz (2010), and Beatty and Joffe (2006). These studies show that the influences of others in the workplace, particularly managers, are pivotal to the retention of capable individuals with chronic illness or other disabilities in the workplace. Charmaz points out that 'how people with disabilities, their employers and co-workers resolve their respective dilemmas, contributes to where a specific disabled employee's experience falls in the continuum between acceptance and ostracism' (2010: 12). 


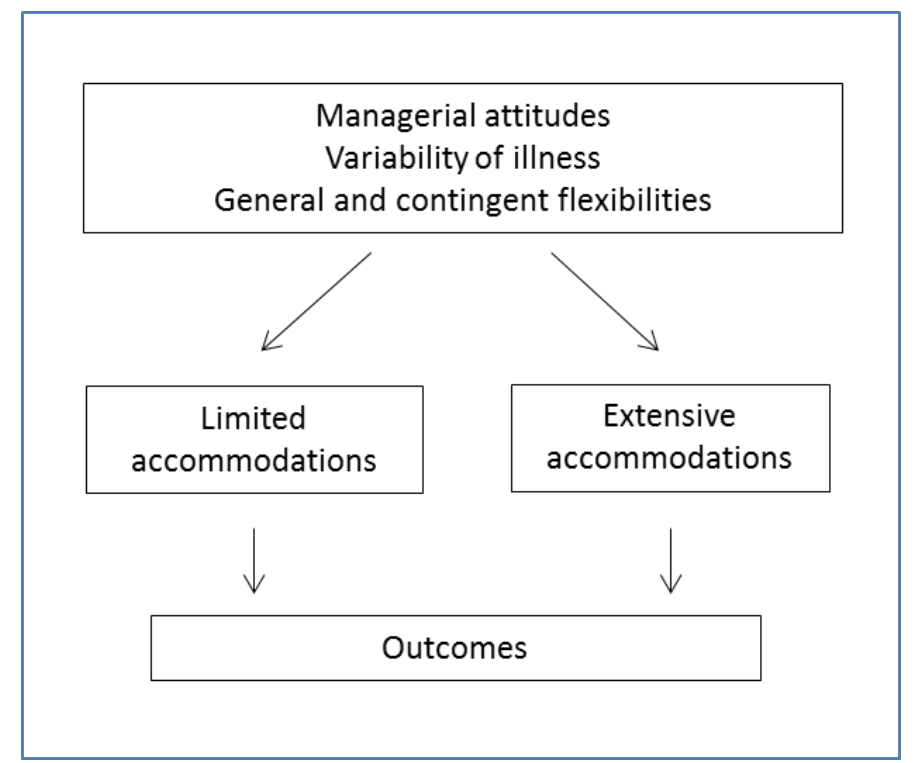

Figure 1: Simplified disclosure contingency pathways

Two types of flexibilities exist in the workplace. General flexibilities are those which are available to permanent employees, such as leave for holidays or for illness. Contingent flexibilities are the special types of leave which might allow a worker time to attend regular specialist appointments and understanding that those appointments may take longer than an average medical appointment (Werth, 2013). The National Disability Forum survey found that flexible workplace practices are 'an essential precondition to the successful and ongoing employment of persons with disabilities’ (Australian Human Rights Commission, 2014: 13). The availability of flexibilities and the positive or negative managerial attitudes are linked. Where a manager is understanding and approves contingent flexibilities they are also likely to exhibit positive attitudes. Vickers (2012) found that the inverse is also likely be the case.

There is a growing volume of literature addressing the difficulties created by severity and variability of illness or disability. Goffman (1986) first identifies issues associated with an inconsistent persona. He identifies the differentiation that is possible when a person falls outside an expected social category. 'When a stranger comes into our presence, then first appearances are likely to enable us to anticipate his category and attributes, his "social identity" ... We lean on these anticipations that we have, transforming them into normative expectations...' (1986: 2). Inability to conform with these normative expectations results in the reduction of 'a whole and usual person to a tainted, discounted one' (Goffman, 1986: 2). Individuals with chronic illness face this type of assessment within their workplaces. Other authors identify issues specific to illness or disability and work. These include: Myers (2004), Pinder (1996), Vickers (2003; 2001), Beatty (2012) and McGonagle (2011). Themes of workplace understanding, difficulty where there is limited flexibility, and the need to disclose intensely personal information in an attempt to access understanding and flexibility, are key to these analyses. We see here that managerial attitudes, flexibility and severity and variability of illness interact contingently to create either a positive or less positive working environment. These interactions will ultimately determine the workforce outcomes of the worker with chronic illness or disability.

\section{Methodology}

Qualitative analysis provides an opportunity 'to achieve substantive or formal theoretical advancement' (Scambler and Hopkins, 1990: 1189). The purpose of researching the impact of disease on the identity of the individual 'can be best served by providing authentic data, 
namely collecting and displaying evidence on the experiential side of how chronic illness and its treatment affect a person' (Gerhardt, 1990: 1149). The narratives of these women provided insight into lives affected by illness has the potential to reveal little understood concepts which are useful for building theory specific to chronic illness. Concepts and meanings associated with life affected by illness can be 'fluid, indefinite and changeable' (Barzun and Graff, 2004: 103). The essence of these meanings needs to be drawn out, analysed and developed into relevant theory which is essential to improving the working lives of people affected by chronic illness. There is a possibility that women with illness may experience a 'deterioration of self-conception [which] may effectively undermine the normalisation strategies adopted’ (Gerhardt, 1990: 1154). A number of themes (Braun and Clark, 2006) were drawn out of the data: attitudes of managers, the variability of illness and the various flexibilities are the key contingencies that will be examined in this article.

Participants were sourced through support groups for chronic illnesses, networks of support services and union newsletters to facilitate a greater spread of characteristics such as type of employment, level of position and pay. A number of support groups were canvassed to access participants: these included, Kidney Health Australia, Australian Crohn's and Colitis Association and the Multiple Sclerosis Society of Australia. This range of support groups was contacted so that participants with different forms of chronic illness could be accessed for the study. The LHMU (Liquor, Hospitality and Miscellaneous Workers Union, now called United Voice) included information on the study in their newsletter. This union was targeted as a way to access participants who were more likely to be employed in casual and lower paying work roles. The range of occupations of women included a cleaner, a coffee shop attendant, but also nurses, a town planner, a lecturer and a lawyer. Some of these women were employed on a casual basis, while others were in permanent positions.

Participants were interviewed using a semi-structured format. Interviews were recorded with the consent of the interviewee and recordings were transcribed verbatim. Questions asked related to topics such as: details of diagnosis, impact of illness on actual work and working conditions, disclosure of illness, details of work, union membership, work history, illness history, attitudes to working with illness, and demographic data. Themes were extracted from the transcriptions through a coding process, using NVivo8 qualitative data analysis software (QSR International, 2008).

\section{Insider methodology}

The concept of insiderness is important in the study of stigmatised and, often invisible, types of illness. As an individual who was diagnosed with a chronic illness more than 25 years ago, I have experienced many phases of life with the symptoms, medication outcomes and medical constraints of the disease. Being an insider, as described by Merton means, 'you have to be one in order to understand one' (1972:15). He describes insiders in terms of what outsiders are not able to achieve:

The outsider has neither been socialized in the group nor has engaged in the run of experience that makes up its life, and therefore cannot have the direct, intuitive sensitivity that alone makes empathetic understanding possible (Merton, 1972: 15).

A number of the women interviewed seemed willing to explain their difficulties because they expected me to understand owing to the extent of my own illness. Merton sees insiderness as defined by the privileged access of individuals to 'particular kinds of knowledge' (1972: 11). The role of an insider researcher more readily allows access to a reality which may differ considerably from that of a researcher who is not an insider. The objective was to achieve a richness of data within the comfort zone of the participant. This is achievable with an insider researcher as Merton points out that 'only through continued socialisation in the life of a 
group can one become fully aware of its symbolisms and socially shared realities' (Merton, 1972: 15).

Vickers noted, in her experience as an insider researcher, that 'one of the most notable and heartening manifestations was the [participants] apparent desire to talk to me and to tell their story' (Vickers, 2001a: 53). The insider researcher has an advantage in these circumstances because of the stigma associated with talking about one's experiences of illness: there is an opportunity to negotiate the cultural barriers and access greater information. Vickers commented that 'the revelation of [her] illness assisted in obtaining deeper, richer and more personally held information from respondents' (2001a: 46). The value of researching the area as an insider was evident when participants would say, in essence, 'You should understand this, this is where you've been'.

The thought of sharing personal or embarrassing information with an outsider researcher, could be enough to stop individuals from participating in the research. Despite this, some participants made the point that the research was important. Maree commented, 'I find it really interesting that someone has decided to do this research project because I suspect it happens a lot more than we know.' She was referring to the difficulties women with chronic illness experience in their workplaces. Mary made the point, 'I think the Government puts it in the too hard basket and you've got too many ministers who have never experienced anything more than what they know now.' There was a feeling amongst those in the study that people generally do not understand the difficulties associated with chronic illness. Undertaking the research as an insider was important in order to access the most valuable data.

There is debate over whether insider research are is essential to accessing information that may not, for various reasons, be available to outsiders. Nevertheless, key elements of the research on chronic illness and work have been completed by insiders, including DenzPenhey (1997), Vickers (1997), Myers (2004), Nielsen (2007) as well as the theses of Beatty (2004), and Morris (2003). There are perspectives presented in this paper which are unique to insider research.

\section{Why women?}

Women are participating in the workforce in greater numbers than ever, they have faced changes in family structure, and they have taken on greater challenges (Whitehouse, 2004a). Increasing levels of workforce participation by individuals with chronic illness means that these challenges may be more significant than some work-life research has anticipated. Women who might already experience disadvantage because of their caring responsibilities, may find that they do not have the flexibility needed in their working arrangements to also manage a chronic illness. Pocock argues that:

The fact that individuals have different preferences, that these change over time (often in unpredicted ways), and that many work and care events arise not from preferences but circumstances beyond individual control, means that policy should provide a menu of options that accommodates diverse situations (2003: 245).

'Diverse situations changing in unpredicted ways' is a neat summation of the situation in which many carers find themselves when also confronting the difficulties of illness. 'Many women workers struggle to escape low-paid jobs, partly because of the ongoing absence of adequate public and workplace supports for working carers' (Masterman-Smith and Pocock 2008: 41). Pocock comments that, 'at present caring responsibilities remain in the main with women, and most are done in the private sphere of the home, family and extended family' (Pocock 2003:205). Social expectations of how women manage caring roles have resulted in women arranging their specific caring circumstances from outside the workplace. These 
expectations have a curious parallel to the social requirements of those with illness. Organisations expect that illness circumstances belong in the private domain of workers and they may fail to make the necessary accommodation available.

In the already-limited research on workers with chronic illness, there has been an even more restricted focus on the specific circumstances of women in this group, although the number of studies that are not gender-specific is increasing. Studies that specifically focus on the impact of working on women with chronic illness include those by Vickers $(1997,2001 \mathrm{~b}$, 2003b), Myers (2004), Pryce, Munir and Haslam (2007) and Myers and Grasmick (1990). The research by Jones, Latrielle and Sloane (2006) on disability and gender examines issues of productivity and differentiates between work-limiting and non-work-limiting disability. Vickers' studies, in particular, find that women with chronic illness are often denied the 'assumption of competence' in their place of employment. Vickers found, for example, that women may be offered token flexibility at work such as improved accessibility of meeting venues, but for this benefit they may be required to perform duties when they should have been allowed to take sick leave (1998).

\section{Workplace experiences: managerial attitudes}

Traditional expectations of work and illness allocate particular roles to those who are ill (Parsons, 1970). Employers may regard individuals with illness as unproductive, inconsistent and undesirable workers (Vickers, 2003). This is fuelled by a tendency to be unsure of appropriate ways to treat individuals in these circumstances. Symptoms of chronic illness differ between individuals and may also relapse and remit, making it difficult to maintain a capable working identity. The understandings that supervisors or employers have of what it means to work with a particular illness, influence the accommodations that those workers are able to access. Supervisors may perceive that illness is a 'personal issue beyond the organisation's domain [where] employees are expected to manage the situation on their own' (Beatty and Joffe, 2006: 189). These socially fostered beliefs are likely to limit the individual's workforce outcomes.

Workers may choose strategies of disclosure or non-disclosure, based on the support which management provides for those with illness. Other options may include undertaking work at a lower level to assist with symptoms, or seeking work in a more understanding workplace. Charmaz (2010) found that where workers were established and valued within the organisation, employers were more likely to approve requests for accommodations. However, the possibility of discrimination or negative reactions of colleagues 'shapes how people manage information about their illness at work' (Beatty and Joffe, 2006: 186). The helpful attitudes of organisational managers towards those with illness are more likely to influence co-workers and result in positive work outcomes for chronically ill employees (Beatty and Joffe, 2006).

Pinder notes that 'there is ample evidence, both documented and anecdotal, that disabled people are disadvantaged in the labour market' (Pinder, 1995: 605). Policies that allow for formal accommodations for employees with illness should reflect the disabling effects of different chronic conditions (Charmaz, 2010). A common misconception is that managing individuals with illness is in conflict with an economically productive business environment which is defined in terms of unquestioned assumptions about the need for 'constant involvement and productivity, speed, coordinated timing, regular schedules and predictable performance levels’ (Charmaz, 2010: 10).

\section{Debbie and Jane}

Participants in this study reported the value of having the support of their supervisor. Debbie made the point that she avoided stress because it 'might trigger a flare' of her disease. To 
minimise stress, she thought it was beneficial to have considerate bosses, to whom she could say, 'Look, you know I live with this, and I'm well at the moment, but there is a possibility that I might not be well.' She felt that she 'would like to have that support.' However, Jane reported that her boss was unwilling to grant her any form of understanding or accommodations at work, wanting her to take leave and only return when she had recovered. Jane's illness was one where short term recovery was improbable as nine years had elapsed since her diagnosis. She commented that she had consistently been passed over for career enhancing opportunities which had been offered to more junior staff members.

\section{Samantha}

Samantha experienced significant discrimination on the basis of her diabetes while working as a coffee shop attendant. Her bosses wanted Samantha and her friend (who also had diabetes) to resign, and when they refused, management decreased their rostered hours. Her friend's mother sought legal help, which enabled Samantha to continue in that workplace. Despite the protection of legislation, overt discrimination on the basis of illness may still occur in workplaces. Samantha's experience highlights just how vulnerable casual workers can be, particularly in highly casualised industries such as hospitality.

Samantha worked in a variety of positions. When she returned to the workforce, after a break because of illness, she experienced more obvious negative attitudes to her illness from management in a new position. She and John were selected from a group of disabled people who were participants in an assisted return to work program, to work in traineeship positions with a government department.

There were two trainees put on at the time, John was in a wheelchair and I had the diabetes. And [management] said that we were the best of a bad bunch.

This was an open expression of the underlying intolerant attitudes that management in that department held towards disabled people. Samantha explained:

But because we had the computer skills and the communication skills from other [employment], we got the jobs. We were doing well. Towards the end of the traineeship I started getting sick. Of course, I'd had about one and a half months off in full, not [all at once] in that time. When it came up they said they weren't going to offer me the position because of my unreliability.

Later in the interview, Samantha revisited the situation at that workplace and added:

When I was at [the government department, when I was sick], I was always hospitalised, so it wasn't a case of, I was sick at home.

Employers may dislike workers who appear to be taking unwarranted sick leave. When the amount of sick leave is an issue, the validity of the illness may also be brought into question. This does not appear to be the case for Samantha, although she was concerned about appearing to be credible. Her boss, at the government department, openly made negative comments regarding disability as well as undertaking discriminatory actions. Samantha said, 'I considered appealing, but honestly, I'd just had enough.' Individuals with illness, at times need to consider their health and chances of success before arguing for their rights in a work environment which is lacking in understanding.

Samantha, in a number of positions, battled against management perceptions regarding the severity of her illness. Achieving formal accommodations proved to be difficult for Samantha because of both the severity and variability of her illness. Samantha's limited labour market power, her employment in casual positions and difficult disease meant that she found it difficult to achieve outcomes at work which would assist with the management of her illness. She decided to leave those places of employment because of the negative 
supervisory attitudes encountered. As shown in the simplified disclosure contingency pathways diagram, her workforce outcomes were shaped by the ways in which the negative attitudes of her employer and the lack of workplace accommodations interacted with her illness and her limited bargaining power.

\section{Maree}

Maree was a young graduate nurse who suffered from epilepsy and who experienced some harassment and possible discrimination on the basis of her illness:

It got to the point where they were watching me all the time because, I found out after the fact, that they were afraid I would have a seizure while I was holding a child. And then that put them at risk of liability... I said to them, 'That would never happen because I always get enough of a warning [of an epileptic fit] that I can put down a child.' But because of that they were watching me all the time. And then, every little mistake I made they would pick on it. Until one day, I had absolutely no warning [from management] whatsoever, I had no formal conversations with my manager or my staff development nurse or anything like that, it was just one day I came to work and I got this message, 'You have to go and see the Director of Nursing,' whom I'd never met before, might I add. And I had no idea what it was about. And I rocked up on time and there was the Director of Nursing, my nurse manager and the staff development nurse, all sitting across the table and me by myself on the other side.

Maree went on to say that a colleague had made a written complaint regarding what amounted to a misunderstanding. Her colleague took the complaint to the Director of Nursing, but Maree was not provided with an opportunity to present her side of the story until she was called to the meeting with senior staff. They said to her:

I was a dangerous nurse, I was a terrible nurse, I was just a death waiting to happen. And noone was standing up for me. It was pretty nasty. They sent me home, and I promptly went to the razor blades and tried to slash my wrists. Lucky my husband was there.

As a graduate nurse Maree was well educated, and she knew how to manage her job as well as her illness, but encountered misunderstanding and intolerance in her workplace. It should be noted that Maree's seizures differed from those which are commonly expected of those with epilepsy, being rather more subdued. When she felt one coming on she would stop what she was doing, take her glasses off and sit down. Stigma and misunderstanding of the significance of her type of epilepsy, caused Maree ultimately leave her position. This occurred in a large hospital where she was later advised to make a complaint about her treatment to the industrial tribunal. She decided not to do so:

So, at this point in time, I had two choices. 1) Take them to tribunal, or 2) resign. I left. I considered it for a few weeks... because I didn't want this to happen to someone else. But by the same token I knew that if I went down the tribunal way, it would be my confidence, my career and I knew they would drag every mistake I ever made back out.... And I thought, 'In the end I'm the one that's going to be crushed, it's my word against theirs. I'm probably not going to win and even if I do win, they're still going to make my life hell.' So I decided to cut my losses and move on.

She was subsequently employed at another hospital where she found understanding for her illness and was able to continue working without any difficulties with her colleagues.

\section{Melissa}

Melissa was also a nurse who found it difficult to access formal accommodations at work. She had a number of conditions which made it difficult to work full-time and one which could be life-threatening. When she made a request to reduce her working week to four days instead of full-time, it was initially declined. 
So I ended up going to my GP and got a letter which basically said that I needed to work four days a week for health reasons. And they said, 'That's not good enough: we only accept letters from a specialist.' So then I went to my cardiologist who wrote the same thing. And they said, 'No sorry we've got advice from HR, it's got to be one of our hospital specialists.'

Melissa was happy to comply, but was concerned about the time this would take. She was conscious that she needed to take care of herself, particularly because of her increasing blood pressure. Her manager was aware that she had previously suffered a heart attack, but Melissa felt that her unhelpfulness was to do with 'power control.' When Melissa rang Human Resources to find out the time for her specialist appointment she was told:

'You're not on the list.' And I said 'Well this isn't good enough. I know it often takes months to get into a specialist and we were coming up to Christmas and most of the specialists go away for the whole of January, [and] I need to have time off now.' And then all of a sudden I got told that I wouldn't be getting an appointment with a specialist and I couldn't believe when they told me that. They obviously found out it was going to cost $\$ 750$ for me to have the appointment and to get the appropriate tests would cost them [another] \$750. All of a sudden they were talking about $\$ 1500$ by the time they factored the tests in and they were not going to pay that. And they wouldn't give me the time off.

Melissa's doctor gave her a medical certificate which stated that she needed to have every Wednesday off. However, her workplace required her to have a new medical certificate for each Wednesday. Throughout this time, Melissa reported that her health was going downhill. She tried to be proactive in seeking reduced hours rather than use up her sick leave, but she was unable to access any assistance.

This was HR and my team manager... they were actually forcing me to come to work even though I had doctors' and specialists' letters.

Melissa was vulnerable because of the policies of her workplace. They provided little protection as they were easily used by management to avoid providing the flexibility that Melissa requested, even though their actions were in contravention of the relevant workplace health and safety legislation at the time. In Melissa's case, the attitudes of her employer were detrimental to her health and could have resulted in her resignation, but a change in supervisor resulted in improved workforce outcomes. This is consistent with the simplified contingency pathways model, which suggests that a change in managerial attitudes may in itself have a positive impact on the productivity of a worker with a chronic illness.

Sally

Sally worked as a town planner in a local council. She had not experienced discrimination personally in her workplace, but a friend from her department had and this experience made Sally wary of the attitudes of her supervisor and management. Sally's friend, Sarah, suffered from severe depression and worked as a senior professional in the same workplace. Because of the unpredictability of her illness, management tried to demote Sarah and subsequently she was informed that they needed her to resign or she would be fired, so she resigned. Sally said:

I'm a bit sceptical about going to HR in light of what happened to [Sarah] with her depression. She went to HR, and I think it backfired on her because they were talking to the bosses about what she was saying to HR. So I don't know if HR is really there to help employees. So I'm not game to talk to HR.

Sally was quite distressed about this, in part because of what it meant for her friend, but also what these 'unwritten' policies regarding illness in the workplace mean for her as she continued to work there. Women with chronic illness, such as Sally, may watch the way others with illness are treated in their workplace for clues about appropriate or expected ways 
to act while they are at work. These kinds of understandings about the unwritten rules of their place of employment influence decisions about how or whether to ask for accommodations, which in turn influence their workforce outcomes (as in the simplified disclosure pathways model).

Lucy

Lucy had previously worked as a brand manager in the marketing department of a national company. After a period of time in hospital and a receiving a diagnosis of Crohn's disease, she said that her, 'actual opportunities at work straight away, they were cut.' Lucy found that she was not given the opportunity to apply for a higher level position which was given to another colleague without being advertised. Lucy approached management to find out why she was not given the chance to apply and was told, 'You didn't seem to be wanting to go forward,' a statement which indicated that there was a perception that her diagnosis was related to her willingness to continue her career.

Like Samantha and Maree, Lucy resigned from her position because of negative employer attitudes to their illness. All three subsequently worked in positions where they were successful in managing both their health and their work, as a result of greater understanding from their workplace. Lucy's subsequent role which assisted with understanding for her illness, also gave her flexibility to manage her caring responsibilities for her young children.

\section{General and contingent flexibilities}

General flexibilities consist of those which are available to permanent employees, such as sick leave, recreation leave, and in some workplaces, flexitime. Contingent flexibilities are those which are specifically available to employees with illness. They are often achieved through negotiation, and require disclosure. Where employees are denied support for their illness, they may depend on general flexibilities to manage the difficulties of work and illness.

Emily appeared to have a supportive boss, but despite this she had not disclosed her illness at work. She was able to access her sick leave as she needed, for her medical procedures, without any difficulty. The company policy suggested that they would consider flexibility for their staff. Emily also found her boss understanding of her need for regular, unexplained sick leave, even though she had not disclosed:

Once when I was taking a couple of days off for these day procedures... he said, 'If you ever need more time off...' I think he might even have said, 'If you need different hours or something, we can sort something out.'

Despite not knowing the details of Emily's illness, it seemed that he suspected something and, in keeping with company policy, was willing to provide additional flexibility if she requested it. Emily may have had considerable knowledge and skills as a professional with post-graduate qualifications, but her requests for general flexibilities appeared to be approved because of company policy and a supportive boss. The combination of: a high degree of external labour market power, a relatively well controlled disease, supportive workplace policies and an understanding boss, allowed Emily to continue working without disclosing her illness.

In contrast, Tania was able to access additional contingent flexibilities to assist with her illness. She worked in an administrative role in a large organisation where she had flexibility with the hours she worked:

I'm supposed to work from 8.30am to 4.30pm. If I get here at 9am I just cut a bit off my lunch, or I don't have a lunch or, they just let me do whatever I want, it's just great. 
Tania was able to take rostered days off, and also take annual leave in increments that suited her, rather than in particular blocks of time. She felt that her supervisor was 'really good,' as she allowed her the flexibilities needed to manage her illness. Tania was knowledgeable about her section and the wider organisation, and this provided her with internal labour market power. Her disease was well controlled most of the time, when she needed a break she used a combination of general and contingent flexibilities to achieve this. Tania also had an understanding manager. These factors provided her with the flexibilities she needed to manage her work and illness.

Heather was able to access flexibilities in her workplace. When she had a severe initial flare of her disease, she negotiated with her supervisor for the contingent flexibilities required to facilitate her return to work, initially on a part-time basis. She also continued to access flexibilities for her illness when she returned to her full-time role. These included consideration for some 'space' when she was not feeling well, and flexibility to rest during the day when she needed to continue working into the night. Heather needed to discuss her initial return to work with a new supervisor, who agreed to her proposed hours and days of work. She was a senior public servant, the role gave her extensive labour market power, and her supervisor was prepared to listen to her side of the story. Heather's disease was well controlled and she had considerable control over her work. Her high level of labour market power influenced her ability to access flexibilities for her level of work and her disease. The simplified disclosure pathways show the important influence of positive managerial attitudes on accommodations that are available for women with chronic illness: the more extensive the accommodations the better the workforce outcomes.

On the other hand, Melissa found that she had great difficulty accessing any flexibility. She was prevented from changing working hours by both her supervisor at the time, and the policies of her organisation. A lack of control over her illness and the ready availability of a replacement for her work role contributed to her inability to access the formal accommodations she needed. Only her organisation's need to have a job share arrangement in place for a staff member returning from maternity leave, as well as the arrival of a more understanding supervisor, meant that Melissa was able to access the flexibility she needed to maintain her health.

\section{Discussion and conclusions}

Managerial attitudes were important indicators of success for participants. Negative attitudes were more likely to result in poorer outcomes, even with legislative protection for workers. If negative managerial attitudes were combined with difficult or unpredictable symptoms, it was even more likely that workers would leave their job, as shown in the simplified disclosure contingency pathways (Figure 1). Melissa experienced this, and a change to a more understanding supervisor helped her to achieve better outcomes in her workplace. The difficulties she experienced with organisational policy were resolved by the organisation's subsequent need to find a job share role for a staff member returning from maternity leave. The delay in adjusting Melissa's working hours contributed to the worsening of her illness. Ultimately, Melissa's new supervisor assisted her with accessing the necessary formal accommodations which enabled her to continue working.

Samantha had difficulty accessing the formal accommodations she needed, both to continue working and preserve her health. Balancing work and illness is possible, but there are two factors important in achieving this: firstly, that workplaces comply with their legal responsibility to avoid discriminating against individuals with illness; secondly, that they provide understanding for employees. This may act as a preventative measure by minimising the chances of exacerbating an illness, a requirement under workplace health and safety legislation. Individuals in workplaces where there is a reluctance to comply with legislation 
have little chance of accessing formal accommodations. Should their symptoms worsen they may risk the loss of their position because of the negative attitudes of management. In Samantha's case the birth of her child, and because she had been employed in casual positions, resulted in her exiting the workforce and not seeking another position. Balancing both her caring responsibilities and her health became too difficult to manage.

Managerial attitudes significantly affect the way women with illness manage their careers, request formal accommodations and manage information about their illness in their workplaces. The participants' various working circumstances showed that managerial attitudes influenced the way workplace policies were applied. Debbie, a casual administrative assistant and Jane, a lecturer, worked in the same workplace. Debbie received support for her illness from supervisors, while Jane did not. They worked for a large organisation where there were policies in place to assist those with illness. Maree, after experiencing difficulties in her workplace had contemplated taking her employer to the industrial tribunal but decided that an outcome in her favour could result in her employer making working life even more difficult.

Samantha, owing to the variability of her illness, experienced negative attitudes in a number of workplaces. In one situation, she accessed outside assistance and was able to continue working; in another circumstance she considered appealing against the decision, using workplace policy, but decided she had been through enough, even though it resulted in her loss of employment.

As the interview data show, women with chronic illness commonly made the decision not to fight for their workplace rights. They did this in order to preserve their health. Taking action against an employer for discrimination was often beyond the personal resources of these women. One common area of concern was that after the resolution of their complaint, they would need to return to the same workplace, and still conform to the unwritten requirements of that workplace regarding their illness.

Social expectations of those with illness may lead managers to believe that individuals with illness are potentially unproductive. At times, actions such as the need to take time away from the workplace to attend medical appointments appear to support these assumptions. Managers also seem to be unsure of appropriate ways to work with those with illness, and this may result in a tendency to encourage workers to find work elsewhere because, 'things aren't really working out.' Women in the study had potentially serious illnesses, and where they received support at work, they each had positive outcomes. This finding is supported by the National Disability Forum survey which found that 'many respondents believed that increasing employer awareness, engagement and understanding of disabilities in employment could resolve many discrimination issues in the workplace' (Australian Human Rights Commission, 2014: 11).

The attitudes that women with illness might encounter from their supervisors, managers or employers may stem from whether their illness constitutes a stigmatised identity in relation to their role, their working relationships and the perceptions those in power have about sickness. Working environments which provide support, understanding for the severity and variability of illness, and flexibilities for those with illness, facilitate better overall working outcomes for this group of women.

\section{Acknowledgements}

Thanks go to David Peetz and Kaye Broadbent for their assistance with the development of this paper. This research was undertaken while a doctoral student at Griffith University. The author also thanks the anonymous referees and topic area editor for helpful feedback. 


\section{About the author}

Shalene Werth is a lecturer in employment relations in the Department of Management and Enterprise at the University of Southern Queensland. She has an interest in researching the workforce experiences of people with disability and chronic illness.

\section{References}

Australian Human Rights Commission (2014) National disability forum: summary of survey results. Sydney: AHRC.

Barzun J and Graff HF (2004) The Modern Researcher. $6^{\text {th }}$ ed. Belmont CA: Thomson/Wadsworth and Melbourne VIC: Macmillan.

Beatty JE (2004) Chronic illness as invisible diversity: disclosing and coping with illness in the workplace. Doctoral dissertation. Department of Organisation Studies, The Carroll Graduate School of Management. Boston MA: Boston College.

Beatty JE (2012) Career barriers experienced by people with chronic illness: a US study. Employee Rights and Responsibilities Journal 24 (2): 91-110.

Beatty JE and Joffe R (2006) An overlooked dimension of diversity: the career effects of chronic illness. Organizational Dynamics 35(2): 182-195.

Braun V and Clark V (2006) Using thematic analysis in psychology. Qualitative Research in Psychology 3(2): 77-101.

Charmaz K (2010) Disclosing illness and disability in the workplace. Journal of International Education in Business 3(1/2): 6-19.

Commonwealth of Australia (2010) National Disability Strategy 2010-2020. Canberra: Council of Australian Governments.

Foster D (2007) Legal obligation or personal lottery? Employee experiences of disability and the negotiation of adjustments in the public sector workplace. Work, Employment and Society 21(1): 67-84.

Foster D and Fosh P (2010) Negotiating 'difference': representing disabled employees in the British workplace. British Journal of Industrial Relations 48(3): 560-582.

Foster D and Wass V (2013) Disabiliity in the labour market: an exploration of concepts of the ideal worker and organisational fit that disadvantage employees with impairments. Sociology 47(4): 705-721.

Gerhardt U (1990) Qualitative research on chronic illness: the issue and the story. Social Science and Medicine 30(11): 1139-1159.

Goffman E (1986) Stigma: Notes on the Management of Spoiled Identity. New York: Simon and Schuster Inc.

McGonagle AK (2011) Testing a model of stigma applied to chronic illness in the workplace. Doctoral dissertation. University of Connecticut. Paper AAI3485412. http://digitalcommons.uconn.edu/dissertations/AAI3485412.

Myers KR (2004) Coming out: considering the closet of illness. Journal of Medical Humanities 25(4): 255-270.

Parsons T (1970) The Social System. London: Routledge.

Pinder R (1995) Bringing back the body without the blame? The experience of ill and disabled people at work. Sociology of Health and Illness 17(5): 605-631.

Pinder R (1996) Sick-but-fit or fit-but-sick? Ambiguity and identity at the workplace. In: Exploring the Divide. Edited by Barnes C and Mercer G. Leeds: The Disability Press, pp. 135-156. 
Pocock B (2003) The Work/Life Collision, Sydney: The Federation Press.

QSR International (2008) NVivo qualitative data analysis software. QSR International Pty Ptd Version 8.

Scambler G and Hopkins A (1990) Generating a model of epileptic stigma: the role of qualitative analysis. Social Science and Medicine 30(11): 1187-1197.

Vickers M (1997) Life at work with 'invisible' chronic illness (ICI): the 'unseen', unspoken, unrecognised dilemma of disclosure. Journal of Workplace Learning 9(7): 240-252.

Vickers M (2001) Work and Unseen Chronic Illness: Silent Voices, London: Routledge.

Vickers M (2003) Expectations of consistency in organizational life: stories of inconsistency from people with unseen chronic illness. Employee Responsibilities and Rights Journal 15(2): 85-98.

Vickers M (2012) 'For the crime of being different...': Multiple Sclerosis, teams and stigmatisation at work - lessons from a case study. Employee Responsibilities and Rights Journal 24(3): 177-195.

Vickers M, Bailey J and Parris M (2004) Working mothers of children with chronic illness. Early Childhood Australia 29(1): 39-44.

Werth S (2013) An investigation of the interaction of chronically ill women and their working environments. PhD thesis, Department of Employment Relations and Human Resources. Brisbane: Griffith University.

Williams-Whitt K (2007) Impediments to disability accommodation. Relations Industrielles/Industrial Relations 62(3): 405-432.

Williams-Whitt K and Taras D (2010) Disability and the performance paradox: can social capital bridge the divide? British Journal of Industrial Relations 48(3): 534-559. 
Page 16 